\title{
What controls the seasonal cycle of columnar methane observed by GOSAT over different regions in India?
}

\author{
Naveen Chandra ${ }^{1, a}$, Sachiko Hayashida ${ }^{1}$, Tazu Saeki ${ }^{2, b}$, and Prabir K. Patra ${ }^{2}$ \\ ${ }^{1}$ Faculty of Science, Nara Women's University, Kita-Uoya Nishimachi, Nara 630-8506, Japan \\ ${ }^{2}$ Department of Environmental Geochemical Cycle Research, JAMSTEC, Yokohama 2360001, Japan \\ ${ }^{a}$ now at: Research and Development Center for Global Change, JAMSTEC, Yokohama 2360001, Japan \\ bnow at: Center for Global Environmental Research, National Institute for Environmental Studies, Tsukuba 305-8506, Japan \\ Correspondence to: Naveen Chandra (nav.phy09@gmail.com)
}

Received: Received on 13 - Discussion started: 26 April 2017

Revised: 14 August 2017 - Accepted: 11 September 2017 - Published: 24 October 2017

\begin{abstract}
Methane $\left(\mathrm{CH}_{4}\right)$ is one of the most important shortlived climate forcers for its critical roles in greenhouse warming and air pollution chemistry in the troposphere, and the water vapor budget in the stratosphere. It is estimated that up to about $8 \%$ of global $\mathrm{CH}_{4}$ emissions occur from South Asia, covering less than $1 \%$ of the global land. With the availability of satellite observations from space, variability in $\mathrm{CH}_{4}$ has been captured for most parts of the global land with major emissions, which were otherwise not covered by the surface observation network. The satellite observation of the columnar dry-air mole fractions of methane $\left(\mathrm{XCH}_{4}\right)$ is an integrated measure of $\mathrm{CH}_{4}$ densities at all altitudes from the surface to the top of the atmosphere. Here, we present an analysis of $\mathrm{XCH}_{4}$ variability over different parts of India and the surrounding cleaner oceanic regions as measured by the Greenhouse gases Observation SATellite (GOSAT) and simulated by an atmospheric chemistrytransport model (ACTM). Distinct seasonal variations of $\mathrm{XCH}_{4}$ have been observed over the northern (north of $15^{\circ} \mathrm{N}$ ) and southern (south of $15^{\circ} \mathrm{N}$ ) parts of India, corresponding to the peak during the southwestern monsoon (July-September) and early autumn (October-December) seasons, respectively. Analysis of the transport, emission, and chemistry contributions to $\mathrm{XCH}_{4}$ using ACTM suggests that a distinct $\mathrm{XCH}_{4}$ seasonal cycle over northern and southern regions of India is governed by both the heterogeneous distributions of surface emissions and a contribution of the partial $\mathrm{CH}_{4}$ column in the upper troposphere. Over most of the northern Indian Gangetic Plain regions, up to $40 \%$ of the peak-to-trough amplitude during the southwestern (SW) monsoon season
\end{abstract}

is attributed to the lower troposphere $(\sim 1000-600 \mathrm{hPa})$, and $\sim 40 \%$ to uplifted high- $\mathrm{CH}_{4}$ air masses in the upper troposphere $(\sim 600-200 \mathrm{hPa})$. In contrast, the $\mathrm{XCH}_{4}$ seasonal enhancement over semi-arid western India is attributed mainly $(\sim 70 \%)$ to the upper troposphere. The lower tropospheric region contributes up to $60 \%$ in the $\mathrm{XCH}_{4}$ seasonal enhancement over the Southern Peninsula and oceanic region. These differences arise due to the complex atmospheric transport mechanisms caused by the seasonally varying monsoon. The $\mathrm{CH}_{4}$ enriched air mass is uplifted from a high-emission region of the Gangetic Plain by the SW monsoon circulation and deep cumulus convection and then confined by anticyclonic wind in the upper tropospheric heights $(\sim 200 \mathrm{hPa})$. The anticyclonic confinement of surface emission over a wider South Asia region leads to a strong contribution of the upper troposphere in the formation of the $\mathrm{XCH}_{4}$ peak over northern India, including the semi-arid regions with extremely low $\mathrm{CH}_{4}$ emissions. Based on this analysis, we suggest that a link between surface emissions and higher levels of $\mathrm{XCH}_{4}$ is not always valid over Asian monsoon regions, although there is often a fair correlation between surface emissions and $\mathrm{XCH}_{4}$. The overall validity of ACTM simulation for capturing GOSAT observed seasonal and spatial $\mathrm{XCH}_{4}$ variability will allow us to perform inverse modeling of $\mathrm{XCH}_{4}$ emissions in the future using $\mathrm{XCH}_{4}$ data. 


\section{Introduction}

Methane $\left(\mathrm{CH}_{4}\right)$ is the second most important anthropogenic greenhouse gas (GHG) after carbon dioxide $\left(\mathrm{CO}_{2}\right)$ and accounts for $\sim 20 \%\left(+0.97 \mathrm{~W} \mathrm{~m}^{-2}\right)$ of the increase in total direct radiative forcing since 1750 (Myhre et al., 2013). $\mathrm{CH}_{4}$ is emitted from a range of anthropogenic and natural sources on the Earth's surface into the atmosphere. The main natural sources of $\mathrm{CH}_{4}$ include wetlands and termites (Matthews and Fung, 1987; Cao et al., 1998; Sugimoto et al., 1998). Livestock, rice cultivation, the fossil fuel industry (production and uses of natural gas, oil, and coal), and landfills are the major sectors among the anthropogenic sources (Crutzen et al., 1986; Minami and Neue, 1994; Olivier et al., 2005; Yan et al., 2009). These results also suggest that the Asian region is an emission hotspot of $\mathrm{CH}_{4}$ due to the large number of livestock, intense cultivation, coal mining, waste management, and other anthropogenic activities (EDGAR2FT, 2013).

With a short atmospheric lifetime of about 10 years (e.g., Patra et al., 2011a) and having 34 times more potential to trap heat than $\mathrm{CO}_{2}$ on a mass basis over a 100 -year timescale (Gillett and Matthews, 2010; Myhre et al., 2013), mitigation of $\mathrm{CH}_{4}$ emissions could be the most important way to limit global warming at inter-decadal timescales (Shindell et al., 2009). Better knowledge of $\mathrm{CH}_{4}$ distribution and quantification of its emission flux is indispensable for assessing possible mitigation strategies. However, sources of $\mathrm{CH}_{4}$ are not yet well quantified due to sparse ground-based measurements, which results in limited representation of $\mathrm{CH}_{4}$ flux on a larger scale (Dlugokencky et al., 2011; Patra et al., 2016). Recent technological advances have made it possible to detect spatial and temporal variations in atmospheric $\mathrm{CH}_{4}$ from space (Frankenberg et al., 2008; Kuze et al., 2009), which could fill the gaps left by ground-, aircraft- and shipbased measurements, albeit at a lower accuracy than the in situ measurements. Further, despite the satellite observations having an advantage of providing continuous monitoring over a wide spatial range, the information obtained from passive nadir sensors that use solar radiation at the short-wavelength infrared (SWIR) spectral band is limited to columnar dry-air mole fractions of methane $\left(\mathrm{XCH}_{4}\right)$. This is an integrated measure of $\mathrm{CH}_{4}$ with contributions from the different vertical atmospheric layers, i.e., from the measurement point on the Earth's surface to the top of the atmosphere (up to about $100 \mathrm{~km}$ or more precisely to the satellite orbit).

The South Asia region, consisting of India, Pakistan, Bangladesh, Nepal, Bhutan, and Sri Lanka, exerts a significant impact on the global $\mathrm{CH}_{4}$ emissions, with regional total emissions of $37 \pm 3.7 \mathrm{Tg} \mathrm{CH}_{4}$ of about $500 \mathrm{Tg} \mathrm{CH}_{4}$ global total emissions during the 2000s (Patra et al., 2013). The Indo-Gangetic Plain (IGP) located in the foothills of the Himalayas is one of the most polluted regions in the world, hosts $70 \%$ of coal-fired thermal power plants in India, and experiences intense agricultural activity (Kar et al., 2010). This region is of particular interest mainly due to the coexistence of deep convection and large emission of pollutants (including $\mathrm{CH}_{4}$ ) from a variety of natural and anthropogenic sources. Rainfall during the SW monsoon season causes higher $\mathrm{CH}_{4}$ emissions from the paddy fields and wetlands (e.g., Matthews and Fung, 1987; Yan et al., 2009; Hayashida et al., 2013), while the persistent deep convection results in updraft of $\mathrm{CH}_{4}$-laden air mass from the surface to the upper troposphere during the same season, which is then confined by anticyclonic winds at this height (Patra et al., 2011b; Baker et al., 2012; Schuck et al., 2012). Several other studies have also highlighted the role of convective transport of pollutants (including $\mathrm{CH}_{4}$ ) from the surface to the upper troposphere (400-200 hPa) during the SW monsoon season (July-September) (Park et al., 2004; Randel et al., 2006; Xiong et al., 2009; Lal et al., 2014; Chandra et al., 2016). The dynamical system dominated by deep convection and anticyclone covers mostly the northern Indian region (north of $15^{\circ} \mathrm{N}$ ) due to the presence of the Himalayas and the Tibetan Plateau, while such a complex dynamical system has not been observed over the southern part of India (south of $\left.15^{\circ} \mathrm{N}\right)($ Rao, 1976).

Satellite-based measurements show elevated levels of $\mathrm{XCH}_{4}$ over the northern part of India (north of $15^{\circ} \mathrm{N}$ ) to be particularly high over the IGP during the SW monsoon season (July-September) and over southern India (south of $15^{\circ} \mathrm{N}$ ) during the early autumn season (October-December) (Frankenberg et al., 2008, 2011; Hayashida et al., 2013). Previous studies have linked these high $\mathrm{XCH}_{4}$ levels to the strong surface $\mathrm{CH}_{4}$ emissions particularly from the rice cultivation over the Indian region because they showed statistically significant correlations over certain regions (Hayashida et al., 2013; Kavitha et al., 2016). The differences in the peak of the $\mathrm{XCH}_{4}$ seasonal cycle over the northern and southern regions of India are also discussed on the basis of agricultural practice in India that takes place in two seasons, MayOctober and November-April, respectively. However, inferring local emissions directly from variations in $\mathrm{XCH}_{4}$ is ambiguous, particularly over the Indian regions under the influence of monsoon meteorology, because $\mathrm{XCH}_{4}$ involves contributions of $\mathrm{CH}_{4}$ abundances from all altitudes along the solar light path.

This study attempts for the first time to separate the factors responsible (emission, transport, and chemistry) for the distributions of columnar methane $\left(\mathrm{XCH}_{4}\right)$ over the Asian monsoon region for different altitude segments. The $\mathrm{XCH}_{4}$ mixing ratios are used for this study as observed from GOSAT and simulated by JAMSTEC's ACTM. We aim to understand relative contributions of surface emissions and transport in the formation of $\mathrm{XCH}_{4}$ seasonal cycles over different parts of India and the surrounding oceans. This understanding will help us in developing an inverse modeling system for estimation of $\mathrm{CH}_{4}$ surface emissions using $\mathrm{XCH}_{4}$ observations and ACTM forward simulation. 


\section{Methods}

\subsection{Satellite data}

The Greenhouse gases Observing SATellite (GOSAT) (also referred to as Ibuki) project is developed jointly by the National Institute for Environmental Studies (NIES), Ministry of the Environment (MOE), and Japan Aerospace Exploration Agency (JAXA). It has been providing columnar dryair mole fractions of the two important greenhouse gases $\left(\mathrm{XCH}_{4}\right.$ and $\left.\mathrm{XCO}_{2}\right)$ at near-global coverage since its launch in January 2009. It is equipped onboard with the Thermal And Near infrared Sensor for carbon Observation-Fourier Transform Spectrometer (TANSO-FTS) and the Cloud and Aerosol Imager (TANSO-CAI) (Kuze et al., 2009). To avoid cloud contamination in the retrieval process, any scene with more than 1 cloudy pixel within the TANSO-FTS IFOV is excluded. The atmospheric images from CAI are used to identify the cloudy pixels. As a result of this strict screening, only limited numbers of $\mathrm{XCH}_{4}$ data are available during the SW monsoon over South Asia. This study uses the GOSAT SWIR $\mathrm{XCH}_{4}$ (Version 2.21)-Research Announcement product for the period of 2011-2014. The ground-based FTS measurements of $\mathrm{XCH}_{4}$ by the Total Carbon Column Observing Network (TCCON) (Wunch et al., 2011) are used extensively to validate the GOSAT retrievals. Retrieval bias and precision of column abundance from GOSAT SWIR observations have been estimated as approximately $15-20 \mathrm{ppb}$ and $1 \%$, respectively, for the NIES product using TCCON data (Morino et al., 2011; Yoshida et al., 2013).

\subsection{Model simulations}

Model analysis is comprised of simulations from JAMSTEC's atmospheric general circulation model (AGCM)based chemistry-transport model (ACTM; Patra et al., 2009). The AGCM was developed by the Center for Climate System Research/National Institute for Environmental Studies/Frontier Research Center for Global Change (CCSR/NIES/FRCGC). It has been part of transport model intercomparison experiment TransCom- $\mathrm{CH}_{4}$ (Patra et al., 2011a) and used in inverse modeling of $\mathrm{CH}_{4}$ emissions from in situ observations (Patra et al., 2016). The ACTM runs at a horizontal resolution of T42 spectral truncations $\left(\sim 2.8^{\circ} \times 2.8^{\circ}\right)$ with 67 sigma-pressure vertical levels. The evolution of $\mathrm{CH}_{4}$ at different longitude $(x)$, latitude $(y)$, and altitude $(z)$ with time in the Earth's atmosphere depends on the surface emission, chemical loss, and transport, which can be mathematically represented by the following continuity equation:

$$
\begin{aligned}
& \frac{\mathrm{dCH}_{4}(x, y, z, t)}{\mathrm{d} t}=S_{\mathrm{CH}_{4}}(x, y, t)-L_{\mathrm{CH}_{4}}(x, y, z, t) \\
& -\nabla \phi(x, y, z, t),
\end{aligned}
$$

where $\mathrm{CH}_{4}$ is the methane burden in the atmosphere, $\mathrm{S}_{\mathrm{CH}_{4}}$ is the total emissions/sinks of $\mathrm{CH}_{4}$ at the surface, $L_{\mathrm{CH}_{4}}$ is the total loss of $\mathrm{CH}_{4}$ in the atmosphere due to the chemical reactions, and $\nabla \phi$ is the transport of $\mathrm{CH}_{4}$ due to the advection, convection, and diffusion.

The meteorological fields of ACTM are nudged with reanalysis data from the Japan Meteorological Agency, version JRA-25 (Onogi et al., 2007). The model uses an optimal OH field (Patra et al., 2014) based on a scaled version of the seasonally varying OH field (Spivakovsky et al., 2000). The a priori anthropogenic emissions are from the Emission Database for Global Atmospheric Research (EDGAR) v4.2 FT2010 (http://edgar.jrc.ec.europa.eu). The model sensitivity for emission is examined by two cases of emission scenarios based on different combinations of sectoral emissions. The first one is referred to as the "AGS", where all emission sectors in EDGAR42FT are kept at a constant value for 2000, except for emissions from agriculture soils. The second one is a controlled emission scenario referred to as "CTL", which is based on the ensemble of the anthropogenic emissions from EDGAR32FT (as in Patra et al., 2011a), wetland and biomass burning emissions from Fung et al. (1991), and rice paddy emission from Yan et al. (2009). The emission seasonality differs substantially between the CTL case and the AGS case due to differences in emissions from wetlands, rice paddies, and biomass burning; other anthropogenic emissions do not contain seasonal variations (Patra et al., 2016). Further details about the model and these emission scenarios can be found in the previous studies (Patra et al., 2009, 2011a, 2016).

$\mathrm{XCH}_{4}$ is calculated from the ACTM profile using the following equations:

$X \mathrm{CH}_{4}=\sum_{n=1}^{60} \mathrm{CH}_{4}(n) \times \Delta \sigma_{p}(n)$,

where $\mathrm{CH}_{4}(n)$ is the dry-air mole fraction at model midpoint level, $n=$ number of vertical sigma pressure layers of ACTM (=1-60 with $\sigma_{p}$ values of 1.0 and 0.005), and $\Delta \sigma_{p}=$ thickness of the sigma pressure level. Note here that we have not incorporated convolution of model profiles with retrieval a priori and averaging kernels. Because the averaging kernels are nearly constant in the troposphere (Yoshida et al., 2011), this approximation does not lead to serious errors in constructing the model $\mathrm{XCH}_{4}$. For both the CTL and AGS cases, we adjust a constant offset of $20 \mathrm{ppb}$ to the modeled time series, which should make the a priori correction have a lesser impact on the model $\mathrm{XCH}_{4}$. Because the focus of this study is seasonal and spatial variations in $\mathrm{XCH}_{4}$, a constant offset adjustment should not affect the main conclusions. 


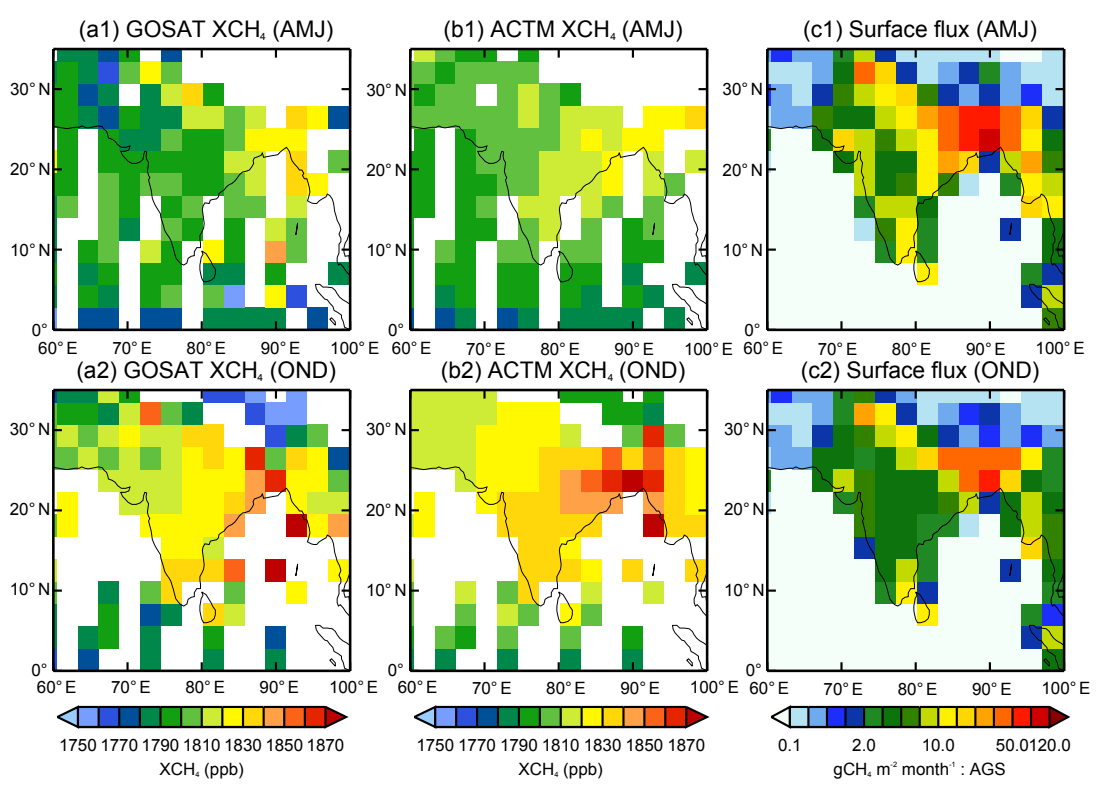

Figure 1. Average seasonal distributions (from 2011 to 2014) of $\mathrm{XCH}_{4}$ obtained from GOSAT observations (a1, a2), ACTM simulations (b1, b2), and $\mathrm{CH}_{4}$ emission consisting of all the natural and anthropogenic emissions (c1, c2: ACTM_AGS case) over the Indian region. Optimized emissions are shown from a global inversion of surface $\mathrm{CH}_{4}$ concentrations (Patra et al., 2016) and multiplied by a constant factor of 12 for a clear visualization. The ACTM is first sampled at the location and time of GOSAT observations and then seasonally averaged. The white spaces in first two columns $(\mathbf{a 1}, \mathbf{a} 2, \mathbf{b 1}, \mathbf{b 2})$ are due to the missing data caused by satellite retrieval limitations under cloud cover.

\section{Results and discussion}

\section{1 $X \mathrm{CH}_{4}$ over the Indian region: view from GOSAT and ACTM simulations}

This section presents an analysis of $X_{\mathrm{CH}_{4}}$ observed by GOSAT from January 2011 to December 2014 over the Indian region. We characterize the four seasons specific to the region as winter (January-March), spring (April-June), summer (July-September) or the SW monsoon, and autumn (October-December), as commonly used in meteorological studies (e.g., Rao, 1976). To study the seasonal $\mathrm{XCH}_{4}$ pattern in detail depending on the distinct spatial pattern of surface emissions and $\mathrm{XCH}_{4}$ mixing ratios shown in Fig. 1, the Indian landmass was partitioned into eight sub-regions: Northeast India (NEI), Eastern India (EI), Eastern IGP (EIGP), Western IGP (WIGP), Central India (CI), Arid India (AI), Western India (WI), Southern Peninsula (SP), and two surrounding oceanic regions, the Arabian Sea (AS) and the Bay of Bengal (BOB) (Fig. 2a). Regional divisions are made based on spatial patterns of emission and $\mathrm{XCH}_{4}$ (Fig. 1a1c2) and our knowledge of seasonal meteorological conditions. Since general features of $\mathrm{XCH}_{4}$ simulated by ACTM using emission scenarios AGS and CTL are similar to each other, the main discussion is carried out using the AGS scenario only.

Figure 1a1-a2 show that the $\mathrm{XCH}_{4}$ mixing ratios are lower in spring and higher in autumn. A strong latitudinal gradient in $\mathrm{XCH}_{4}$ is observed between the Indo-Gangetic Plain (IGP) and the other parts of India. $X \mathrm{CH}_{4}$ shows the highest value $(\sim 1880 \mathrm{ppb})$ over the IGP, eastern, and northeastern Indian regions. As seen from Fig. 1b1-b2, ACTM simulations are able to reproduce the observed latitudinal and seasonal gradients in $\mathrm{XCH}_{4}$, i.e., higher values during the southwestern monsoon and autumn seasons and lower values during the winter and spring seasons over the IGP region. The optimized total $\mathrm{CH}_{4}$ fluxes (AGS and CTL) show high emissions over the IGP and northeastern Indian regions (Fig. 1c1-c2). Most elevated levels of $\mathrm{XCH}_{4}$ are often observed simultaneously with the higher emissions, suggesting a link between the enhanced $\mathrm{XCH}_{4}$ and high surface emissions in summer. However, this link is not valid for all locations. For example, over the western and southern regions of India, $\mathrm{XCH}_{4}$ is higher in autumn than in spring, though the emissions are higher in spring.

Figure 2b-k show ACTM-GOSAT comparisons of $\mathrm{XCH}_{4}$ time series from January 2011 to December 2014 over the selected study regions. The simulated $\mathrm{XCH}_{4}$ data are sampled at the nearest model grid to the available GOSAT observations and at the satellite overpass time $(\sim 13: 00 \mathrm{LT})$ and then averaged over each study region. Observations are sparse or not available during the SW monsoon season in some of the regions due to limitations of GOSAT retrieval under cloud cover. The model captures the salient features of the seasonal cycles at very high statistical significance (correlation coefficients, $r>0.8$; except for northeastern India; Table 1). The high ACTM-GOSAT correlations for the low-/no-emission regions suggest that transport and chemistry are accurately 


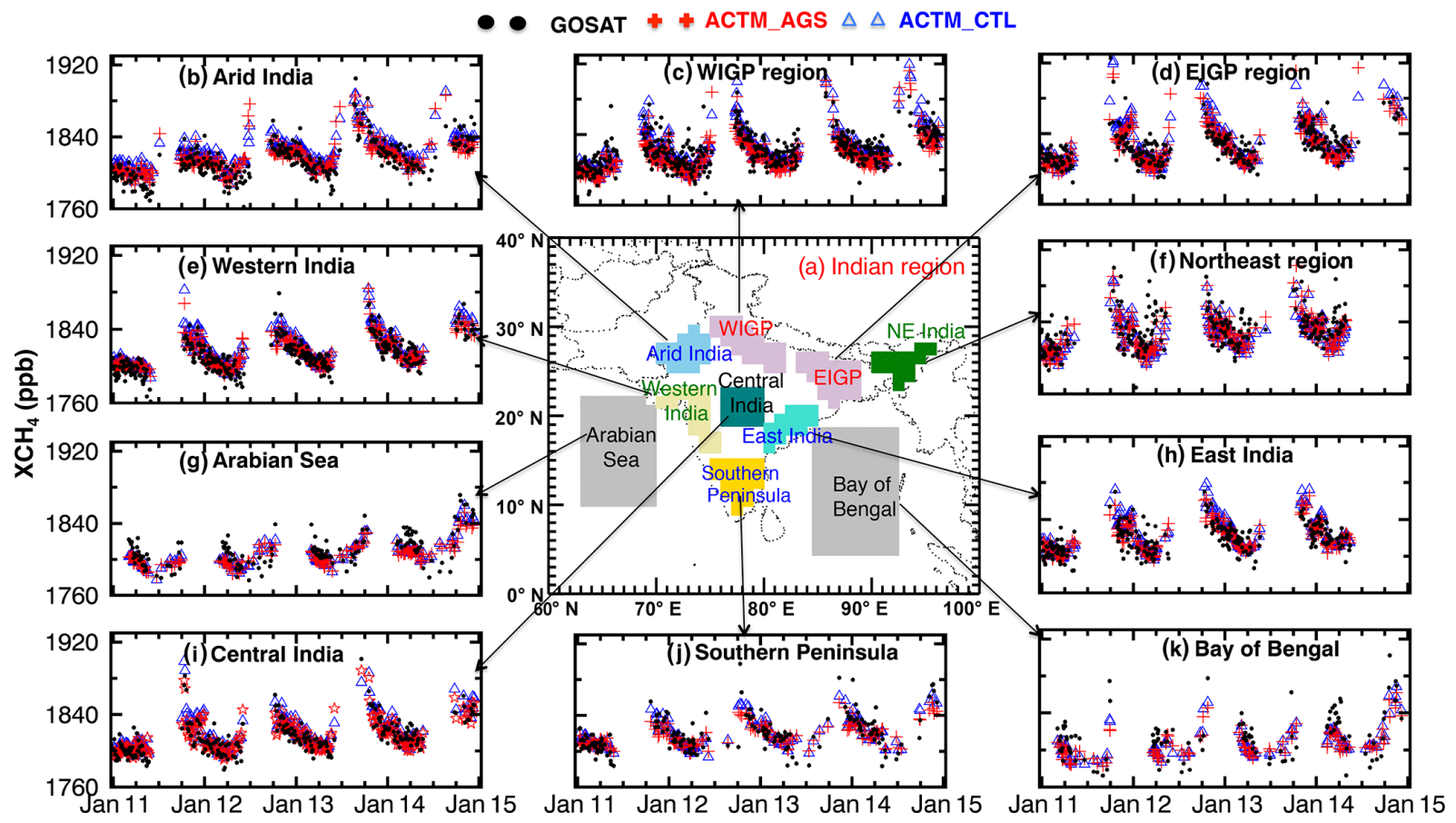

Figure 2. (a) The map of the regional divisions (shaded) for the time series analysis. (b-k) Time series of $\mathrm{XCH}_{4}$ over the selected regions (shown on the map) as obtained from GOSAT and simulated by ACTM for two different emission scenarios, namely, ACTM_AGS and ACTM_CTL. The gaps are due to the missing observational data.

modeled in ACTM. Although we do not have the statistically significant number of observations for the SW monsoon period, the observed high GOSAT $\mathrm{XCH}_{4}$ are generally well simulated by ACTM over most of the study regions. Based on these comparisons, we can assume that model simulations can be used to understand $\mathrm{XCH}_{4}$ variability over the Indian region. Though we showed only the paired GOSAT and ACTM data that matched in time and location in Fig. 2b$\mathrm{k}$, we also confirmed that the correlation is high $(r \sim 0.9)$ between the monthly averaged time series of GOSAT and ACTM averaged for the 4 years (2011-2014) when ACTM is not co-sampled at the GOSAT sampling points (Fig. S1 in the Supplement). These high correlations ensure representativeness of the data shown in Fig. 2b-k. Thus, the seasonal evolution of $\mathrm{XCH}_{4}$ using the ACTM simulations alone is expected to be fairly valid for different altitude layers (refer to Patra et al., 2011b, for comparison at the aircraft cruising altitude). Though the model is only validated for $\mathrm{XCH}_{4}$ in this study, comparisons with surface and independent aircraft $\mathrm{CH}_{4}$ observations have been shown in Patra et al. (2016).

\subsection{Seasonal cycle of $\mathrm{XCH}_{4}$ and possible controlling factors}

As mentioned earlier, the persistent deep convection and mean circulation during the SW monsoon season significantly enhance $\mathrm{CH}_{4}$ in the upper troposphere (e.g., Xiong et al., 2009; Baker et al., 2012), coinciding with the period
Table 1. Correlation coefficients $(r)$ between observed and model simulated seasonal cycles of $\mathrm{XCH}_{4}$. Model simulations are obtained from ACTM using two different emission scenarios, AGS and CTL.

\begin{tabular}{lcc}
\hline Site/tracer & ACTM_AGS & ACTM_CTL \\
\hline Arid India & 0.77 & 0.88 \\
WIGP region & 0.86 & 0.90 \\
EIGP region & 0.69 & 0.88 \\
Northeast India & 0.55 & 0.55 \\
Western India & 0.87 & 0.95 \\
Central India & 0.89 & 0.97 \\
East India & 0.78 & 0.86 \\
Southern Peninsula & 0.92 & 0.91 \\
Arabian Sea & 0.86 & 0.87 \\
Bay of Bengal & 0.84 & 0.86 \\
\hline
\end{tabular}

of high surface $\mathrm{CH}_{4}$ emissions due to rice paddy cultivation and wetlands over the Indian region (Yan et al., 2009; Hayashida et al., 2013). Although both these emissions and transport processes contribute greatly to seasonal changes in $X \mathrm{CH}_{4}$, their relative contributions have not been studied over the monsoon-dominated Indian region.

To understand the role of transport, the atmospheric column is segregated into five sigma-pressure $\left(\sigma_{p}\right)$ layers, starting from the surface level $\left(\sigma_{p}=1\right)$ to the top of the atmosphere $\left(\sigma_{p}=0\right)$, with an equal layer thickness of $\sigma_{p}=0.2$. 


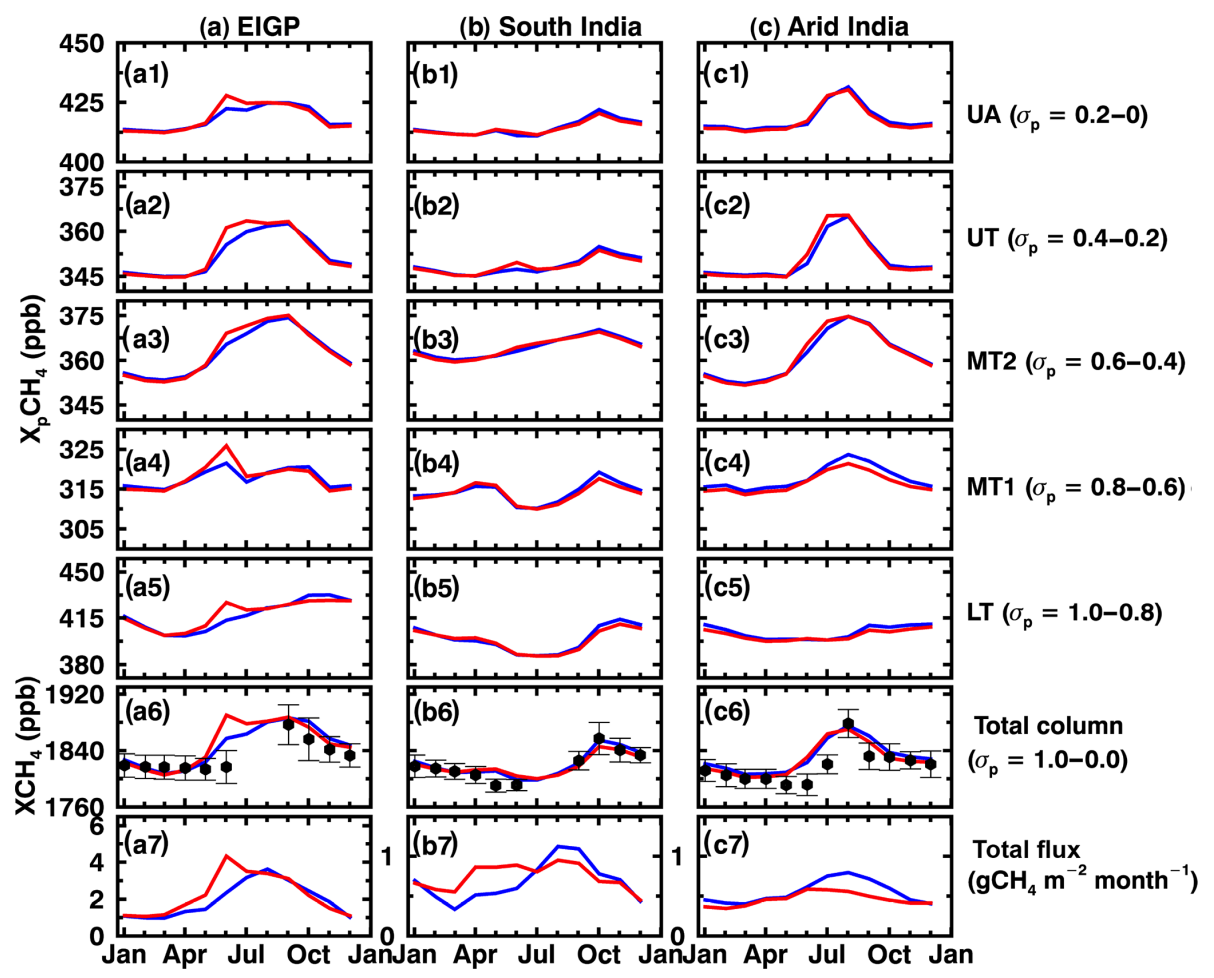

Figure 3. The bottom panels show the monthly mean climatology of the total optimized $\mathrm{CH}_{4}$ emissions (a7, b7, c7), estimated after performing the global inverse analysis (Patra et al., 2016). The second bottom panels show $\mathrm{XCH}_{4}$ obtained from the GOSAT observations (black circles in a6, b6, c6) and ACTM simulations (a6, b6, c6) over the Eastern IGP (column a), Southern Peninsula (column b) and Arid India (column c) regions. Monthly climatology is based on the monthly mean values for the period of 2011-2014 for all the values. The error bars in the GOSAT monthly mean values depict the 1- $\sigma$ SDs for the corresponding months (a6, b6, c6). The 1- $\sigma$ values are not plotted for the model simulations to maintain figure clarity. Simulations are based on two different emission scenarios, namely, ACTM_CTL (blue lines) and ACTM_AGS (red lines) based on the different combinations of emissions. The upper five panels show the monthly climatology of partial columnar methane (denoted by $\left.X_{p} \mathrm{CH}_{4}\right)$ calculated at five different partial sigma-pressure layers: $1.0-0.8(\mathbf{a 5}, \mathbf{b 5}, \mathbf{c 5}), 0.8-0.6(\mathbf{a 4}, \mathbf{b 4}, \mathbf{c 4})$, $0.6-0.4(\mathbf{a 3}, \mathbf{b 3}, \mathbf{c 3}), 0.4-0.2(\mathbf{a 2}, \mathbf{b 2}, \mathbf{c 2})$, and $0.2-0.0(\mathbf{a 1}, \mathbf{b 1}, \mathbf{c 1})$. Please note that the $y$ scales in the emission plots over the Southern Peninsula and Arid India (b7, c7) are different from over the EIGP region (a7).

Lower Troposphere (LT), Mid-Troposphere1 (MT1), MidTroposphere2 (MT2), Upper Troposphere (UT), and Upper Atmosphere (UA) denote the layers corresponding to the sigma-pressure values of $1.0-0.8,0.8-0.6,0.6-0.4,0.4-0.2$, and $0.2-0.0$. The partial columnar $\mathrm{CH}_{4}$ is calculated within different $\sigma_{p}$ layers (denoted by $X_{p} \mathrm{CH}_{4}$ ) using the same formula for $\mathrm{XCH}_{4}$, as in Sect. 2.2. The model results are averaged over each sub-region of our analysis for the $\mathrm{XCH}_{4}$ seasonal cycle. To understand the role of surface emission in the $\mathrm{XCH}_{4}$ seasonal cycle, the climatology of the optimized total $\mathrm{CH}_{4}$ flux for each sub-region is compared. Figure 3 shows the monthly mean climatology (average for 2011-2014) of total $\mathrm{CH}_{4}$ flux, $\mathrm{XCH}_{4}$, and $X_{p} \mathrm{CH}_{4}$ from the model averaged over three selected regions, EIGP (a1-a7), SP (b1-b7), and AI (c1-c7). These representative regions have been selected because they show distinct $\mathrm{XCH}_{4}$ seasonal cycles and the dominant controlling factors (such as emission, transport, and chemistry). The observed GOSAT $\mathrm{XCH}_{4}$ values are also shown for a reference; however, the model results do not correspond to the location and time of GOSAT observations (as opposed to those in Fig. 2). The plots for the remaining seven regions are available in Figs. S2 and S3.

Over the EIGP region, the magnitude and timing of the seasonal peak in emission differ substantially between the CTL and AGS emission scenarios (refer to Fig. 3a7). ACTM simulated $\mathrm{XCH}_{4}$ seasonal peak is in agreement with the peak in emission in June for the AGS case (Fig. 3a6). However, simulated $\mathrm{XCH}_{4}$ remains nearly constant until September, although the emission decreases substantially toward winter. In general, the emission is relatively higher in the monsoon season (July-August-September) than in other seasons in both cases. However, in the LT, where we expect most susceptibility to the surface emission, the partial column $\mathrm{CH}_{4}$ indicates very different seasonality from the emissions; $X_{p} \mathrm{CH}_{4}$ (LT) increases toward winter continuously (Fig. 3a5). The partial $\mathrm{CH}_{4}$ columns for the upper troposphere and middle troposphere (Fig. 3a2-a3) show similar seasonality to the total $\mathrm{XCH}_{4}$ rather than in the LT. Therefore, this analysis strongly suggests that the emissions from the surface and the upper tropospheric partial column both 
contribute to the formation of the $\mathrm{XCH}_{4}$ seasonal cycle. These results also suggest the possibility that GOSAT and ACTM $X \mathrm{CH}_{4}$ data can be used for correcting a priori emission scenarios by inverse modeling.

In contrast to the $\mathrm{XCH}_{4}$ seasonal cycle over EIGP, a notable difference is observed in the emission and $\mathrm{XCH}_{4}$ seasonal cycle over the SP region (Fig. 3b). The $\mathrm{XCH}_{4}$ seasonal cycle and emission seasonal cycle are found to be out of phase with each other and the differences in emission scenarios are not reflected in $\mathrm{XCH}_{4}$ seasonal variations. Both emission scenarios show the distinct seasonal pattern: AGS shows annual high emissions from April to September, while CTL shows an annual high during August-September (Fig. 3b7). The total emissions over SP are much lower than that of EIGP (note the different $y$ axis scale for Fig. 3b7) and hence the difference between the $\mathrm{XCH}_{4}$ simulations from both emission scenarios is comparatively low. The $\mathrm{XCH}_{4}$ shows almost identical seasonal cycles for both of the emission scenarios, a peak in October, and prolonged low values during May-September. The seasonal $X_{p} \mathrm{CH}_{4}$ cycle in the LT layer shows the seasonal pattern similar to the total $\mathrm{XCH}_{4}$. Inconsistency between emission seasonality and $X \mathrm{CH}_{4}$ coupled with low emissions strongly suggests that the $X_{\mathrm{CH}_{4}}$ can be controlled by transport and/or chemistry but not emissions. Surface winds during May-September over SP are of marine origin, which effectively flushes the air with low $\mathrm{CH}_{4}$ (see Fig. S4). Further, the distinct seasonal cycle of chemical loss is observed over the SP region compared to other study regions; the loss rate starts increasing from $6 \mathrm{ppbday}^{-1}$ in January to $12 \mathrm{ppbday}^{-1}$ in April, and continues to remain high until September (refer to Fig. S5). These pieces of evidence clearly suggest that the combined effect of transport and chemistry causes the low $\mathrm{XCH}_{4}$ values for the May-September period over the SP region. The peaks in the upper layers in October (Fig. 3b1-b4) and transport from the polluted continental layer in the LT layer (refer to Fig. S4) could together contribute to the seasonal $\mathrm{XCH}_{4}$ peak over SP. Based on these findings, we conclude that the $\mathrm{XCH}_{4}$ measurements do not impose a strong constraint on surface emissions for inverse modeling over the SP region, suggesting a need for in situ measurements.

Over the Arid India (AI) region, the $\mathrm{XCH}_{4}$ seasonal cycle is observed to be different from those of the EIGP and SI regions. The simulated $\mathrm{XCH}_{4}$ (Fig. 3c6) shows extremely weak sensitivity to the surface emission differences between the AGS and CTL cases (Fig. 3c7). Additionally, the $X_{p} \mathrm{CH}_{4}$ in the LT layer (Fig. 3c5) does not resemble the phase of seasonality in surface emissions and simulated/observed $\mathrm{XCH}_{4}$. The $X_{p} \mathrm{CH}_{4}$ in the LT layer decreases from January to August and increases until December. On the other hand, a remarkable peak $(\sim 1896 \mathrm{ppb})$ is observed in $\mathrm{XCH}_{4}$ during August, followed by a decline afterward (Fig. 3c6). This is an outstanding example of deceiving linkage between surface emissions and $\mathrm{XCH}_{4}$ in terms of seasonal variation. An enhancement in the mixing ratios of $X_{p} \mathrm{CH}_{4}$ is observed from

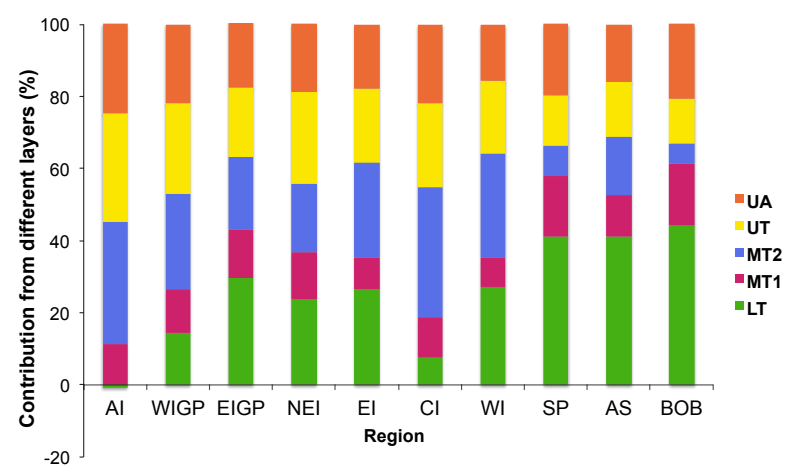

Figure 4. Contributions of partial columns in the seasonal amplitude of $\mathrm{XCH}_{4}$ over selected regions for the AGS case. Differences in the $X_{p} \mathrm{CH}_{4}$, calculated at the same time as the maxima and minima of the seasonal $\mathrm{XCH}_{4}$ cycle, are used to calculate the percentage contributions of respective partial columns in the seasonal amplitude of $\mathrm{XCH}_{4}$

May to August only in the MT2 and UT layers (Fig. 3c2c3) and from June to August in the UA layer (Fig. 3c1). This analysis infers that MT2 and UT partial columns mostly contribute to the formation of the $\mathrm{XCH}_{4}$ seasonal cycle over the AI region.

Next, we quantify the contributions of different partial layers $\left(X_{p} \mathrm{CH}_{4}\right)$ in the formation of $\mathrm{XCH}_{4}$ seasonal amplitude (Fig. 4). As the phase of the $\mathrm{X}_{p} \mathrm{CH}_{4}$ seasonal cycle does not always match with that of $\mathrm{XCH}_{4}$, we have fixed months of peak and trough in the $\mathrm{XCH}_{4}$ seasonal cycle for this analysis. First, we calculate the differences of the $X_{p} \mathrm{CH}_{4}$ values at the time of the peak and the trough of the $\mathrm{XCH}_{4}$ over each region, and then the differences at different partial layers are divided by the seasonal amplitude of $\mathrm{XCH}_{4}$ for calculating the contributions from the respective layers into the seasonal amplitude of $\mathrm{XCH}_{4}$.

Figure 4 reveals that $\sim 40 \%$ of the seasonal enhancement in the observed $\mathrm{XCH}_{4}$ can be attributed to the partial pressure layers below $600 \mathrm{hPa}$ (LT and MT1) for the EIGP region, which is directly influenced by the surface emissions. About $40 \%$ in seasonal enhancement comes from layers above $600 \mathrm{hPa}$. Over the SP region, about $60 \%$ of the seasonal $\mathrm{XCH}_{4}$ amplitude is attributed to layers below $600 \mathrm{hPa}$ and the remaining $40 \%$ results from the upper layers. Although the activities in the lower atmosphere (below $600 \mathrm{hPa}$ ) govern most of the seasonal $\mathrm{XCH}_{4}$ cycle over this region, there is no clear link with seasonal variations in emissions as this region is under greater influence of changes in monsoon meteorology. These regions are under the influence of emission signals from the Indian subcontinent during winter, while in the summer, clean marine air controls $\mathrm{CH}_{4}$ levels (see also Patra et al., 2009). In contrast to the two regions mentioned above, over the AI region, the LT and MT1 layers together contribute only about $12 \%$ to the formation of the $\mathrm{XCH}_{4}$ seasonal cycle amplitude, and the layers above $600 \mathrm{hPa}$ con- 

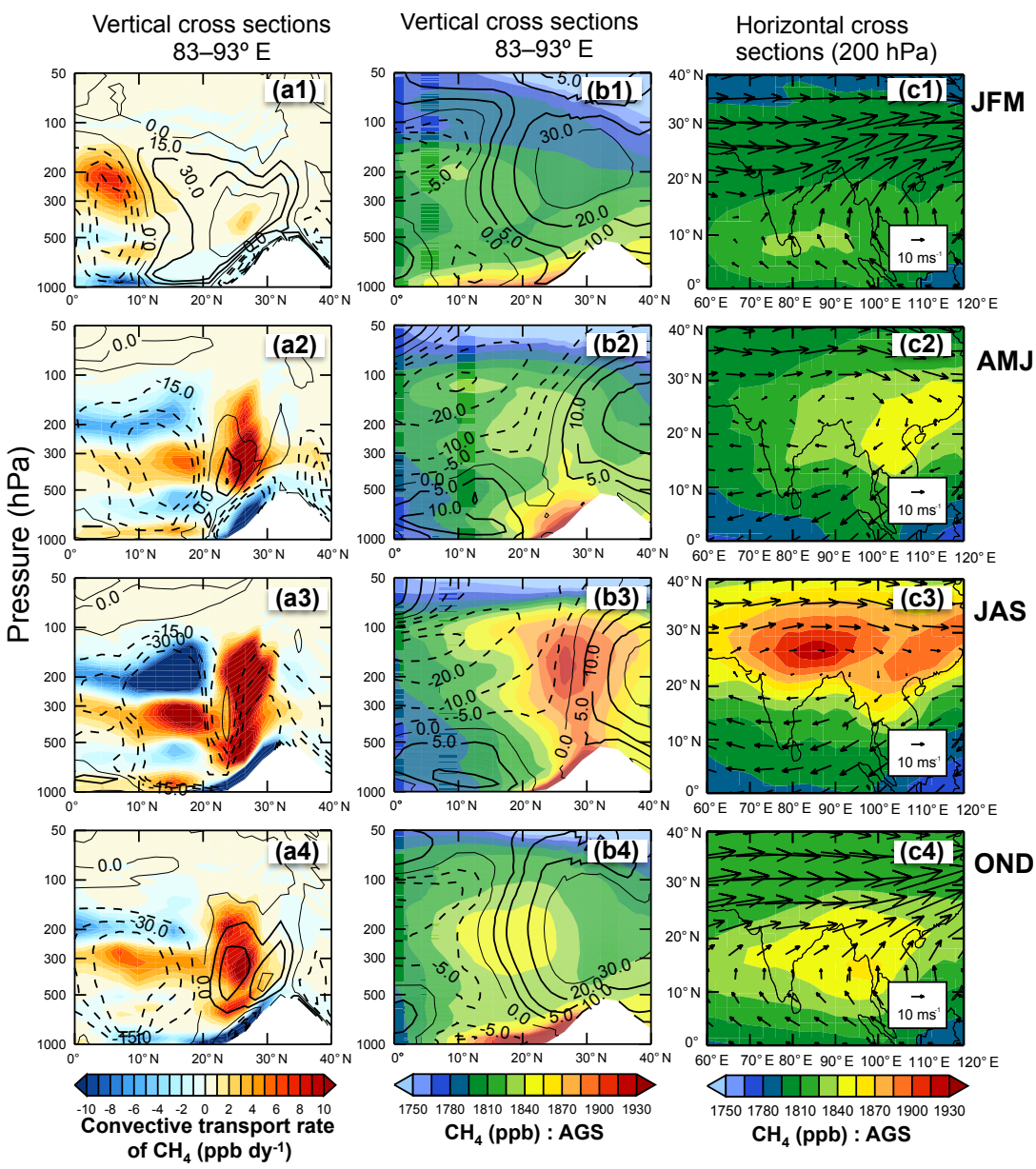

Figure 5. Vertical structure of seasonally averaged $\mathrm{CH}_{4}$ transport rate due to the convection (a1-a4, in ppbday $\left.{ }^{-1}\right)$ and $\mathrm{CH}_{4}$ mixing ratios (b1-b4 from AGS scenarios) averaged over $83-93^{\circ}$ E for the year 2011. Positive and negative transport rate values represent the accumulation and dissipation of mass, respectively. The contour lines in the first (a1-a4) and second (b1-b4) columns depict the average omega velocity (in $\mathrm{hPas}^{-1}$ ) and $u$ wind component, respectively, for the same period. The solid contour lines show the positive values and the dotted lines show negative values. Positive and negative values of the omega velocity represent downward and upward motions, respectively. The zero value of $u$ wind indicates that the wind is either purely southerly or northerly. White spaces in zonal-mean plots (a1-b4) show the missing data due to orography. The rightmost column (c1-c4) depicts the maps of averaged $\mathrm{CH}_{4}$ and wind vectors (in $\mathrm{m} \mathrm{s}^{-1}$; arrow) during all four seasons in 2011 at $200 \mathrm{hPa}$ height.

tribute the remaining $88 \%$. These findings lead us to conclude that instead of surface emissions, the high $\mathrm{CH}_{4}$ in the upper tropospheric layers contributes significantly to the formation of seasonal peaks in $\mathrm{XCH}_{4}$.

\subsection{Source of high $\mathrm{CH}_{4}$ in the upper troposphere}

The reason for high mixing ratios in the upper troposphere, as discussed in the previous section, can be explained by vertical transport of high $\mathrm{CH}_{4}$ emission signals from the surface, because the vertical transport timescales in the tropical region are much shorter than the chemical lifetime of $\mathrm{CH}_{4}$, on the order of 1-2 years (Patra et al., 2009). Figure 5a1-a4 show the latitude-pressure cross sections of the convective transport rate (in $\mathrm{ppb} \mathrm{day}^{-1}$ ) and vertical velocity $\left(\mathrm{hPa} \mathrm{s}^{-1}\right.$ ) averaged over $83-93^{\circ} \mathrm{E}$ for the different seasons of 2011 (the ACTM AGS case). The positive/negative values of the convective transport rate and vertical velocity in Fig. 5a1a4 indicate the gain/loss of mass and downward/upward motions, respectively. Rapid updrafts of $\mathrm{CH}_{4}$, as indicated by higher negative vertical velocity, by deep convection during the monsoon season are aided by the regional topography of the IGP region (north of $20^{\circ} \mathrm{N}$ and east of $79^{\circ} \mathrm{E}$ in the Indian region). These updrafts lift $\mathrm{CH}_{4}$-rich air into the upper tropospheric region (Fig. 5b3). The $\mathrm{CH}_{4}$ concentrations at the surface level decreased rapidly at an average rate of $\sim 10 \mathrm{ppb} d a y^{-1}$ during the SW monsoon season, and accumulate in the upper troposphere at a similar rate over the IGP region (Fig. 5a3). During the winter, spring, and autumn seasons surface $\mathrm{CH}_{4}$ decreased at an average rate of 2,8 , and 7 ppb day $^{-1}$, respectively. $\mathrm{CH}_{4}$ levels accumulate in the mid- 
dle and upper troposphere at an average rate of 6 ppbday $^{-1}$ during the spring and autumn seasons, while during the winter season no significant accumulation has been observed at this height over the IGP region (Fig. 5a1, a2, and a4). Overall these transport processes repeat every year with a certain degree of interannual variation, as can be seen for the years from 2011 to 2014. The interannual variations are likely to have been caused by the early/late onset and retreat of the SW monsoon as well as the weak/strong monsoon activity over the years.

The horizontal cross sections of $\mathrm{CH}_{4}$ at $200 \mathrm{hPa}$ are shown with wind vectors in Fig. 5c1-c4 for understanding the spatial extent of uplifted $\mathrm{CH}_{4}$-rich air over the whole South Asian region. The uplifted $\mathrm{CH}_{4}$-rich air mass is trapped in the upper troposphere $(\sim 200 \mathrm{hPa})$ when encountered by the anticyclonic winds during the SW monsoon season. This leads to a widespread $\mathrm{CH}_{4}$ enhancement covering a large part of South Asia, and the $\mathrm{CH}_{4}$-rich air leaked predominantly along the southern side of the sub-tropical westerly jet over to East Asia (Fig. 5c3; see also Umezawa et al., 2012). As a result of this, the high $\mathrm{CH}_{4}$ air masses at the upper troposphere are not limited to the regions of intense surface emissions as discussed earlier. After the SW monsoon season, the strong westerly jet breaks the upper tropospheric anticyclone and the $\mathrm{CH}_{4}$-rich air mass shifts over southern India during the autumn season (Fig. 5c4). In this way, the convective updraft of high- $\mathrm{CH}_{4}$ air mass, followed by horizontal spreading of the air mass over the larger area by anticyclonic circulation, controls the redistribution of $\mathrm{CH}_{4}$ in the upper troposphere over the northern part of India during the SW monsoon season, and over the Southern Peninsula during the early autumn season.

\section{Conclusions}

The seasonal variations in dry-air mole fractions of methane $\left(\mathrm{XCH}_{4}\right)$ measured by the Greenhouse gases Observation SATellite (GOSAT) are analyzed over India and the surrounding seas using JAMSTEC's atmospheric chemistrytransport model (ACTM). The region of interest (the Indian landmass) is divided into eight sub-regions, namely, Northeast India (NEI), Eastern India (EI), Eastern IGP (EIGP), Western IGP (WIGP), Central India (CI), Arid India (AI), Western India (WI), Southern Peninsula (SP), and two surrounding oceanic regions, the Arabian Sea (AS) and the Bay of Bengal (BOB). The ACTM simulations are conducted using a couple of surface fluxes optimized by the inverse analysis as described in Patra et al. (2016). We have shown that the distinct spatial and temporal variations of $\mathrm{XCH}_{4}$ observed by GOSAT are governed not only by the heterogeneity in surface emissions, but also by complex atmospheric transport mechanisms caused by the seasonally varying Asian monsoon. The seasonal $\mathrm{XCH}_{4}$ patterns often show a fair correlation between emissions and $\mathrm{XCH}_{4}$ over the regions resid- ing in the northern half of India (north of $15^{\circ} \mathrm{N}$ : NEI, EI, EIGP, WIGP, CI, WI, AI), which would imply $\mathrm{XCH}_{4} \mathrm{lev}-$ els are closely associated with the distribution of emissions on the Earth's surface. However, detailed analysis of transport and emission using ACTM over these regions (except for AI) reveals that about $40 \%$ of seasonal enhancement in the observed $\mathrm{XCH}_{4}$ can be attributed to the lower tropospheric layer (below $600 \mathrm{hPa}$ ). The lower tropospheric layers are affected either by the surface emissions, e.g., in the northern India regions or seasonal changes in horizontal winds due to monsoon for the SP region. Up to $40 \%$ of the seasonal $\mathrm{CH}_{4}$ enhancement is found to come from the uplifted air mass into the $600-200 \mathrm{hPa}$ height layer over northern regions in India. In contrast, over the semi-arid AI region, as much as $\sim 88 \%$ of contributions to the $\mathrm{XCH}_{4}$ seasonal cycle amplitude came from the height above $600 \mathrm{hPa}$, and only $\sim 12 \%$ are contributed by the atmosphere below $600 \mathrm{hPa}$. The primary cause of the higher contributions from above $600 \mathrm{hPa}$ over the northern Indian region is the characteristic of air mass transport mechanisms in the Asian monsoon region. The persistent deep convection during the southwestern monsoon season (June-August) causes strong updrafts of $\mathrm{CH}_{4}$ rich air mass from the surface to upper tropospheric heights $(\sim 200 \mathrm{hPa})$, which is then confined by anticyclonic winds at this height. The anticyclonic confinement of surface emission over a wider South Asia region leads to strong contribution of the upper troposphere in formation of the $\mathrm{XCH}_{4}$ peak over most regions in northern India, including the semi-arid regions with extremely low $\mathrm{CH}_{4}$ emissions. In contrast to these regions, over the SP region, the major contributions (about $60 \%)$ to $\mathrm{XCH}_{4}$ seasonal amplitude come from the lower atmosphere $(\sim 1000-600 \mathrm{hPa})$. Both transport and chemistry dominate in the lower troposphere over the SP region and thus the formation of the $\mathrm{XCH}_{4}$ seasonal cycle is not consistent with the seasonal cycle of local emissions. As the upper level anticyclone does not cover the southern Indian region during the active phase of southwestern monsoon, no enhancement in $\mathrm{XCH}_{4}$ is observed over the Southern Peninsula region.

This study shows that ACTM simulations are capturing the GOSAT observed seasonal and spatial $\mathrm{XCH}_{4}$ variability well, and results provide an improved understanding of emissions, chemistry, and transport of $\mathrm{CH}_{4}$ over one of the strongest global monsoonal regions.

Data availability. The satellite GOSAT records used in this study are available on the GOSAT official website (https://data2.gosat. nies.go.jp/index_en.html). The model simulation data could be available on request. The corresponding author and Prabir Patra (prabir@jamstec.go.jp) may be contacted for the same.
The Supplement related to this article is available online at https://doi.org/10.5194/acp-17-12633-2017- supplement. 
Competing interests. The authors declare that they have no conflict of interest.

Acknowledgements. The Environment Research and Technology Development Fund (A2-1502) of the Ministry of the Environment, Japan, supported this research. The authors would like to thank the entire GOSAT team for their many years of hard work in producing the data. We also thank both the reviewers for constructive comments, which improved the contents of this article significantly.

Edited by: Manvendra K. Dubey

Reviewed by: two anonymous referees

\section{References}

Baker, A. K., Schuck, T. J., Brenninkmeijer, C. A. M., Rauthe-Schöch, A., Slemr, F., van Velthoven, P. F. J., and Lelieveld, J.: Estimating the contribution of monsoon-related biogenic production to methane emissions from South Asia using CARIBIC observations, Geophys. Res. Lett., 39, L10813, https://doi.org/10.1029/2012GL051756, 2012.

Cao, M., Gregson, K., and Marshall, S.: Global methane emission from wetlands and its sensitivity to climate change, Atmos. Environ., 32, 3293-3299, https://doi.org/10.1016/S13522310(98)00105-8, 1998.

Chandra, N., Venkataramani, S., Lal, S., Sheel, V. and Pozzer, A.: Effects of convection and long-range transport on the distribution of carbon monoxide in the troposphere over India, Atmos. Pollut. Res., 7, 775-785, https://doi.org/10.1016/j.apr.2016.03.005, 2016.

Crutzen, P. J., Aselmann, I., and Seiler, W.: Methane production by domestic animals, wild ruminants other herbivorous fauna and humans, Tellus B, 38, 271-284, https://doi.org/10.1111/j.16000889.1986.tb00193.x, 1986.

Dlugokencky, E. J., Nisbet, E. G., Fisher, R., and Lowry, D.: Global atmospheric methane: budget, changes, and dangers, Philos. T. Roy. Soc. A, 369, 2058-2072, 2011.

EDGAR42FT: Global emissions EDGAR v4.2FT2010, available at http://edgar.jrc.ec.europa.eu/overview.php?v=42FT2010, last access: October 2013.

Frankenberg, C., Bergamaschi, P., Butz, A., Houweling, S., Meirink, J. F., Notholt, J., Petersen, A. K., Schrijver, H., Warneke, T., and Aben, I.: Tropical methane emissions: a revised view from SCIAMACHY onboard ENVISAT, Geophys. Res. Lett., 35, L15811, https://doi.org/10.1029/2008g1034300, 2008.

Frankenberg, C., Aben, I., Bergamaschi, P., Dlugokencky, E. J., van Hees, R., Houweling, S., van der Meer, P., Snel, R., and Tol, P.: Global column-averaged methane mixing ratios from 2003 to 2009 as derived from SCIAMACHY: trends and variability, J. Geophys. Res., 116, D04302, https://doi.org/10.1029/2010JD014849, 2011.

Fung, I., John, J., Lerner, J., Matthews, E., Prather, M., Steele, L. P., and Fraser, P. J.: Three-dimensional model synthesis of the global methane cycle, J. Geophys. Res., 96, 13033-13065, https://doi.org/10.1029/91JD01247, 1991.

Gillett, N. P. and Matthews, H. D.: Accounting for carbon cycle feedbacks in a comparison of the global warming ef- fects of greenhouse gases, Environ. Res. Lett., 5, 034011, https://doi.org/10.1088/1748-9326/5/3/034011, 2010.

Hayashida, S., Ono, A., Yoshizaki, S., Frankenberg, C., Takeuchi, W., and Yan, X.: Methane concentrations over Monsoon Asia as observed by SCIAMACHY: signals of methane emission from rice cultivation, Remote Sens. Environ., 139, 246-256, https://doi.org/10.1016/j.rse.2013.08.008, 2013.

Kar, J., Deeter, M. N., Fishman, J., Liu, Z., Omar, A., Creilson, J. K., Trepte, C. R., Vaughan, M. A., and Winker, D. M.: Wintertime pollution over the Eastern Indo-Gangetic Plains as observed from MOPITT, CALIPSO and tropospheric ozone residual data, Atmos. Chem. Phys., 10, 12273-12283, https://doi.org/10.5194/acp-10-12273-2010, 2010.

Kavitha, M. and Nair, P. R.: Region-dependent seasonal pattern of methane over Indian region as observed by SCIAMACHY, Atmos. Environ., 131, 316-325, https://doi.org/10.1016/j.atmosenv.2016.02.008, 2016.

Kuze, A., Suto, H., Nakajima, M., and Hamazaki, T.: Thermal and near infrared sensor for carbon observation fourier transform spectrometer on the greenhouse gases observing satellite for greenhouse gases monitoring, Appl. Optics, 48, 6716-6733, https://doi.org/10.1364/AO.48.006716, 2009.

Lal, S., Venkataramani, S., Chandra, N., Cooper, O. R., Brioude, J., and Naja, M.: Transport effects on the vertical distribution of tropospheric ozone over western India, J. Geophys. Res.-Atmos., 119, 10012-10026, https://doi.org/10.1002/2014JD021854, 2014.

Matthews, E. and Fung, I.: Methane emissions from natural wetlands: global distribution, area and environmental characteristics of sources, Global Biogeochem. Cy., 1, 61-86, 1987.

Minami, K. and Neue, H. U.: Rice paddies as a methane source, Climatic Change, 27, 13-26, 1994.

Morino, I., Uchino, O., Inoue, M., Yoshida, Y., Yokota, T., Wennberg, P. O., Toon, G. C., Wunch, D., Roehl, C. M., Notholt, J., Warneke, T., Messerschmidt, J., Griffith, D. W. T., Deutscher, N. M., Sherlock, V., Connor, B., Robinson, J., Sussmann, R., and Rettinger, M.: Preliminary validation of column-averaged volume mixing ratios of carbon dioxide and methane retrieved from GOSAT short-wavelength infrared spectra, Atmos. Meas. Tech., 4, 1061-1076, https://doi.org/10.5194/amt-4-1061-2011, 2011.

Myhre, G., Shindell, D., Bréon, F.-M., Collins, W., Fuglestvedt, J., Huang, J., Koch, D., Lamarque, J.-F., Lee, D., Mendoza, B., Nakajima, T., Robock, A., Stephens, G., Takemura, T., and Zhang, H.: Anthropogenic and Natural Radiative Forcing, in: Climate Change 2013: The Physical Science Basis. Contribution of Working Group I to the Fifth Assessment Report of the Intergovernmental Panel on Climate Change, edited by: Stocker, T. F., Qin, D., Plattner, G.-K., Tignor, M., Allen, S. K., Boschung, J., Nauels, A., Xia, Y., Bex, V., and Midgley, P. M., Cambridge University Press, Cambridge, United Kingdom and New York, NY, USA, 659-740, https://doi.org/10.1017/CBO9781107415324.018, 2013.

Olivier, J. G. J., Aardenne, J. A. V., Dentener, F., Ganzeveld, L. N., and Peters, J. A. H. W.: Recent trends in global greenhouse gas emissions: regional trends and spatial distribution of key sources, in: Non- $\mathrm{CO}_{2}$ Greenhouse Gases (NCGG-4), edited by: van Amstel, A., Millpress, Rotterdam, Netherlands, 325-330, 2005.

Onogi, K., Tsutsui, J., Koide, H., Sakamoto, M., Kobayashi, S., Hatsushika, H., Matsumoto, T., Yamazaki, N., Kamahori, H., Taka- 
hashi, K., Kadokura, S., Wada, K., Kato, K., Oyama, R., Ose, T., Mannoji, N., and Taira, R.: The JRA-25 reanalysis, J. Meteorol. Soc. Jpn., 85, 369-432, 2007.

Park, M., Randel, W. J., Kinnison, D. E., Garcia, R. R., and Choi, W.: Seasonal variation of methane, water vapor, and nitrogen oxides near the tropopause: satellite observations and model simulations, J. Geophys. Res., 109, D03302, https://doi.org/10.1029/2003JD003706, 2004.

Patra, P. K., Takigawa, M., Ishijima, K., Choi, B. C., Cunnold, D., Dlugokencky, E. J., Fraser, P., Gomez-Pelaez, A. J., Goo, T. Y., Kim, J. S., Krummel, P., Langenfelds, R., Meinhardt, F., Mukai, H., O'Doherty, S., Prinn, R. G., Simmonds, P., Steele, P., Tohjima, Y., Tsuboi, K., Uhse, K., Weiss, R., Worthy, D., and Nakazawa, T.: Growth rate, seasonal, synoptic, diurnal variations and budget of methane in lower atmosphere, J. Meteorol. Soc. Jpn., 87, 635-663, https://doi.org/10.2151/jmsj.87.635, 2009.

Patra, P. K., Houweling, S., Krol, M., Bousquet, P., Belikov, D., Bergmann, D., Bian, H., Cameron-Smith, P., Chipperfield, M. P., Corbin, K., Fortems-Cheiney, A., Fraser, A., Gloor, E., Hess, P., Ito, A., Kawa, S. R., Law, R. M., Loh, Z., Maksyutov, S., Meng, L., Palmer, P. I., Prinn, R. G., Rigby, M., Saito, R., and Wilson, C.: TransCom model simulations of $\mathrm{CH}_{4}$ and related species: linking transport, surface flux and chemical loss with $\mathrm{CH}_{4}$ variability in the troposphere and lower stratosphere, Atmos. Chem. Phys., 11, 12813-12837, https://doi.org/10.5194/acp-11-128132011, 2011a.

Patra, P. K., Niwa, Y., Schuck, T. J., Brenninkmeijer, C. A. M., Machida, T., Matsueda, H., and Sawa, Y.: Carbon balance of South Asia constrained by passenger aircraft $\mathrm{CO}_{2}$ measurements, Atmos. Chem. Phys., 11, 4163-4175, https://doi.org/10.5194/acp-11-4163-2011, 2011 b.

Patra, P. K., Canadell, J. G., Houghton, R. A., Piao, S. L., Oh, N.H., Ciais, P., Manjunath, K. R., Chhabra, A., Wang, T., Bhattacharya, T., Bousquet, P., Hartman, J., Ito, A., Mayorga, E., Niwa, Y., Raymond, P. A., Sarma, V. V. S. S., and Lasco, R.: The carbon budget of South Asia, Biogeosciences, 10, 513-527, https://doi.org/10.5194/bg-10-513-2013, 2013.

Patra, P. K., Krol, M. C., Montzka, S. A., Arnold, T., Atlas, E. L., Lintner, B. R., Stephens, B. B., Xiang, B., Elkins, J. W., Fraser, P. J., Ghosh, A., Hintsa, E. J., Hurst, D. F., Ishijima, K., Krummel, P. B., Miller, B. R., Miyazaki, K., Moore, F. L., Mühle, J., O’Doherty, S., Prinn, R. G., Steele, L. P., Takigawa, M., Wang, H. J., Weiss, R. F., Wofsy, S. C., and Young, D.: Observational evidence for interhemispheric hydroxyl parity, Nature, 513, 219-223, 2014.

Patra, P. K., Saeki, T., Dlugokencky, E. J., Ishijima, K., Umezawa, T., Ito, A., Aoki, S., Morimoto, S., Kort, E. A., Crotwell, A., Kumar, R., and Nakazawa, T.: Regional methane emission estimation based on observed atmospheric concentrations (2002-2012), J. Meteorol. Soc. Jpn., 94, 91-113, https://doi.org/10.2151/jmsj.2016-006, 2016.

Randel, W. J. and Park, M.: Deep convective influence on the Asian summer monsoon anticyclone and associated tracer variability observed with Atmospheric Infrared Sounder (AIRS), J. Geophys. Res., 111, D12314, https://doi.org/10.1029/2005JD006490, 2006.

Rao, Y. P.: Southwest Monsoon: Synoptic Meteorology, Meteor. Monogr., No. 1/1976, India Meteorological Department, New Delhi, 367 pp., 1976.
Schuck, T. J., Ishijima, K., Patra, P. K., Baker, A. K., Machida, T., Matsueda, H., Sawa, Y., Umezawa, T., Brenninkmeijer, C. A. M., and Lelieveld, J.: Distribution of methane in the tropical upper troposphere measured by CARIBIC and CONTRAIL aircraft, J. Geophys. Res., 117, D19304, https://doi.org/10.1029/2012JD018199, 2012.

Shindell, D. T., Faluvegi, G., Koch, D. M., Schmidt, G. A., Unger, N., and Bauer, S. E.: Improved attribution of climate forcing to emissions, Science, 326, 716-718, https://doi.org/10.1126/science.1174760, 2009.

Spivakovsky, C. M., Logan, J. A., Montzka, S. A., Balkanski, Y. J., Foreman-Fowler, M., Jones, D. B. A., Horowitz, L. W., Fusco, A. C., Brenninkmeijer, C. A. M., Prather, M. J., Wofsy, S. C., and McElroy, M. B.: Three-dimensional climatological distribution of tropospheric $\mathrm{OH}$ : update and evaluation, J. Geophys. Res., 105, 8931-8980, https://doi.org/10.1029/1999JD901006, 2000.

Sugimoto, A., Inoue, T., Kirtibutr, N., and Abe, T.: Methane oxidation by termite mounds estimated by the carbon isotopic composition of methane, Global Biogeochem. Cy., 12, 595-605, https://doi.org/10.1029/98GB02266, 1998.

Umezawa, T., Machida, T., Ishijima, K., Matsueda, H., Sawa, Y., Patra, P. K., Aoki, S., and Nakazawa, T.: Carbon and hydrogen isotopic ratios of atmospheric methane in the upper troposphere over the Western Pacific, Atmos. Chem. Phys., 12, 8095-8113, https://doi.org/10.5194/acp-12-8095-2012, 2012.

Wunch, D., Toon, G. C., Blavier, J.-F. L., Washenfelder, R. A., Notholt, J., Connor, B. J., Griffith, D. W. T., Sherlock, V., and Wennberg, P. O.: The total carbon column observing network, Philos. T. R. Soc. A, 369, 2087-2112, https://doi.org/10.1098/rsta.2010.0240, 2011.

Xiong, X., Houweling, S., Wei, J., Maddy, E., Sun, F., and Barnet, C.: Methane plume over south Asia during the monsoon season: satellite observation and model simulation, Atmos. Chem. Phys., 9, 783-794, https://doi.org/10.5194/acp-9-783-2009, 2009.

Yan, X., Akiyama, H., Yagi, K., and Akimoto, H.: Global estimations of the inventory and mitigation potential of methane emissions from rice cultivation conducted using the 2006 Intergovernmental Panel on Climate Change Guidelines, Global Biogeochem. Cy., 23, GB2002, https://doi.org/10.1029/2008GB003299, 2009.

Yoshida, Y., Ota, Y., Eguchi, N., Kikuchi, N., Nobuta, K., Tran, H., Morino, I., and Yokota, T.: Retrieval algorithm for $\mathrm{CO}_{2}$ and $\mathrm{CH}_{4}$ column abundances from short-wavelength infrared spectral observations by the Greenhouse gases observing satellite, Atmos. Meas. Tech., 4, 717-734, https://doi.org/10.5194/amt-4717-2011, 2011.

Yoshida, Y., Kikuchi, N., Morino, I., Uchino, O., Oshchepkov, S., Bril, A., Saeki, T., Schutgens, N., Toon, G. C., Wunch, D., Roehl, C. M., Wennberg, P. O., Griffith, D. W. T., Deutscher, N. M., Warneke, T., Notholt, J., Robinson, J., Sherlock, V., Connor, B., Rettinger, M., Sussmann, R., Ahonen, P., Heikkinen, P., Kyrö, E., Mendonca, J., Strong, K., Hase, F., Dohe, S., and Yokota, T.: Improvement of the retrieval algorithm for GOSAT SWIR $\mathrm{XCO}_{2}$ and $\mathrm{XCH}_{4}$ and their validation using TCCON data, Atmos. Meas. Tech., 6, 1533-1547, https://doi.org/10.5194/amt-61533-2013, 2013. 